[Postprint version] Please cite as : Ishizaka A, Labib A, A Hybrid and Integrated Approach to Evaluate and Prevent Disasters, Journal of the Operational Research Society, 65(10), 1475-1489, 2013

\title{
A Hybrid and Integrated Approach to Evaluate and Prevent Disasters
}

\author{
Alessio Ishizaka ${ }^{1}$, Ashraf Labib \\ University of Portsmouth, Portsmouth Business School, Richmond Building, Portland Street, \\ Portsmouth PO1 3DE, United Kingdom \\ Emails: Alessio.Ishizaka@port.ac.uk; Ashraf.Labib@port.ac.uk
}

\begin{abstract}
:
Disasters are, by their nature, very complex phenomena. Their modelling using a systematic and logical methodology can help us identify their root causes and may facilitate in allocating appropriate resources to prevent such situations. Although techniques exist to model such phenomena, a single off-the-shelf model is insufficient to provide an effective and realistic analysis to prevent disasters due to its inherent assumptions. In order to overcome these limitations of single methods, this article proposes a hybrid model of four methods to optimise a safety investment. First, a hierarchy is constructed with a problem structuring approach. Secondly, a new graphical representation, the Crisis Tree Analysis (CTA), is introduced to visualize how a combination of basic events may lead to a disaster. Thirdly, the criticality of each event is assessed using the Analytic Hierarchy Process (AHP). Finally, a mathematical programming model is proposed to calculate the optimal allocation of available funds in order to avoid the disaster. A case study of the Bhopal disaster is used to illustrate the proposed four-step method.
\end{abstract}

Keywords: Analytic Hierarchy Process, Crisis Tree Analysis, Mathematical Programming, Risk Management, Bhopal Gas Disaster.

\footnotetext{
${ }^{1}$ corresponding author (tel 0044 (0)2392844171)
} 
[Postprint version] Please cite as : Ishizaka A, Labib A, A Hybrid and Integrated Approach to Evaluate and Prevent Disasters, Journal of the Operational Research Society, 65(10), 1475-1489, 2013

\section{INTRODUCTION}

It is generally observed that the senior executives in companies are concerned mainly with the profitability of their plants/factories. This concern sometimes translates into a decision where safety-related investments appear redundant and non-productive. However, the matter of fact is that industrial accidents regularly happen and sometimes lead to severe human injuries and environmental consequences. Modern history is marked by many such memorable disasters: the Mt. Blanc tunnel fire (Vuilleumier et al. 2002), BP Deepwater Horizon Oil Spill and Offshore Drilling (Skogdalen and Vinnem 2012), Challenger and Columbia explosions (Paté-Cornell and Dillon 2001), Chernobyl (Lindell and Perry 1990) and Fukushima (Gallucci 2012) to name few. Strategic investments are therefore necessary in order to avoid, or at least minimise the risks of having such disasters in future.

The precautionary safety measures are often expensive and uncertain; companies usually do not have unlimited resources (e.g. staff, goods, capital). Therefore allocating resources in such a constrained situation turns out to be a complex decision making problem. The complexity of this problem is primarily due to the subjective nature of risks e.g. it is quite difficult to quantify and control the quality of maintenance or the propriety of management. Although several techniques exist to address such type of problems, each method has its limitations when used in isolation. Some of these techniques include: Fault Tree Analysis (FTA) (Ferdous et al. 2011, Ahmed et al. 2011, Khakzad et al. 2011), Analytic Hierarchy Process (AHP) (Paulos and Apostolakis 1998, Linkov et al. 2006, Steele et al. 2009), Multi Attribute Utility Theory (MAUT) (Apostolakis and Lemon 2005, Cox 2002), Reliability Block Diagram (RBD) (Youngblood 1998, Todinov 2006), Bow-tie (Khakzad et al. 2012), Bayesian network (Khakzad et al. 2011, Khakzad et al. 2013b, Khakzad et al. 2013a), etc.

A stand alone approach may jeopardise the safety issues because the integral modelling of the complex situation is not captured. Therefore, a recent trend is to combine these techniques 
[Postprint version] Please cite as : Ishizaka A, Labib A, A Hybrid and Integrated Approach to Evaluate and Prevent Disasters, Journal of the Operational Research Society, 65(10), 1475-1489, 2013

together e.g. Event Tree, Fault Tree Analysis and Bayesian Updating (Rathnayaka et al. 2011b, Rathnayaka et al. 2011a, Rathnayaka et al. 2012); Fault Tree Analysis and Fuzzy Sets (Ferdous et al. 2009b); Event Tree and Fuzzy Sets (Ferdous et al. 2009a); Bow-tie and Fuzzy Sets (Ferdous et al. 2012, Ferdous et al. 2013).

The objective of this paper is to propose a multiple, yet integrated, approach to model and prevent failures by an optimised and effective resource allocation. The proposed approach facilitates the identification and quantification of all possible risks and also suggests the optimal allocation of resources in order to mitigate them. The successive phases of the proposed approach are:

1. A problem structuring method to build the hierarchy of issues leading to a disaster.

2. A Crisis Tree Analysis (CTA), which graphically display the combination of facts or basic events that may lead to an accident and a Reliability Block Diagram (RBD) which helps analysts to visualise the system functionality and critical components.

3. An adaptation of the Analytic Hierarchy Process in order to quantify the likelihood that a basic event will happen.

4. A knapsack resource allocation, which optimises the investment in safety measures within each basic event.

This article will first describe these methods and then its application on a case study, namely the Bhopal disaster.

\section{INTEGRATED FRAMEWORK}

The four successive phases (Figure 1) of the new conceptual framework are described in this section. Each method used in isolation has its strengths and limitations (Table 1). The problem structuring method is descriptive and helps analysts to understand the problem under consideration. However, being non-prescriptive, it does not solve the problem itself. Similarly, 
[Postprint version] Please cite as : Ishizaka A, Labib A, A Hybrid and Integrated Approach to Evaluate and Prevent Disasters, Journal of the Operational Research Society, 65(10), 1475-1489, 2013

the Fault Tree Analysis is a graphical representation of basic elements but does not provide a criticality index of each element. A progress is made here with the introduction of a new method, Crisis Tree Analysis, which provides an ordinal severity of the crisis. However, the cardinal priority can only be captured with the Analytic Hierarchy Process method. AHP, however, cannot capture the combination of the basics events. A knapsack optimisation can optimise resource allocation but the importance of intangible resources and its connection needs to be defined a priori with another method. Figure 1 explains the input-output connection of each methodology. It is to note here that an experienced user may skip the FTA step and directly jump from problem-structuring to CTA. FTA and CTA are similar, apart from the existence of an additional logic gate (revolving gate) in CTA. The revolving gate can be used in the crisis tree diagram to measure the severity of crisis.

To conclude, each of the discussed methods has its strengths and limitations. In this paper, we propose an integration of all these methods in order to use their strengths and cancel their limitations. The next sections will explain each method in detail.

\begin{tabular}{|l|l|l|}
\hline \multicolumn{1}{|c|}{ Methods } & \multicolumn{1}{|c|}{ Strengths } & \multicolumn{1}{c|}{ Limitations } \\
\hline Problem structuring & $\begin{array}{l}\text { The nature of the problem and its } \\
\text { structure is modelled with a } \\
\text { systematic and complete method. }\end{array}$ & $\begin{array}{l}\text { The method is only descriptive, not } \\
\text { prescriptive. }\end{array}$ \\
\hline FTA & $\begin{array}{l}\text { The combination of the basic } \\
\text { events is graphically modelled. }\end{array}$ & $\begin{array}{l}\text { The criticality of the event cannot } \\
\text { be quantified. }\end{array}$ \\
\hline CTA & $\begin{array}{l}\text { The combination of the basic } \\
\text { events is graphically modelled and } \\
\text { an ordinal severity of the crisis is } \\
\text { measured. }\end{array}$ & $\begin{array}{l}\text { A cardinal criticality of the event } \\
\text { cannot be quantified. }\end{array}$ \\
\hline AHP & $\begin{array}{l}\text { The criticality of the basic events is } \\
\text { quantified. }\end{array}$ & $\begin{array}{l}\text { The combination (AND/OR) of the } \\
\text { basic events cannot be defined. }\end{array}$ \\
\hline $\begin{array}{l}\text { Knapsack } \\
\text { optimisation }\end{array}$ & $\begin{array}{l}\text { The resources allocation is } \\
\text { optimised. }\end{array}$ & $\begin{array}{l}\text { Intangible resources cannot be } \\
\text { quantified and the combination } \\
\text { (AND/OR) of the resources cannot } \\
\text { be defined. }\end{array}$ \\
\hline
\end{tabular}

Table 1 : Strengths and limitations of the safety modelling methods 
[Postprint version] Please cite as : Ishizaka A, Labib A, A Hybrid and Integrated Approach to Evaluate and Prevent Disasters, Journal of the Operational Research Society, 65(10), 1475-1489, 2013

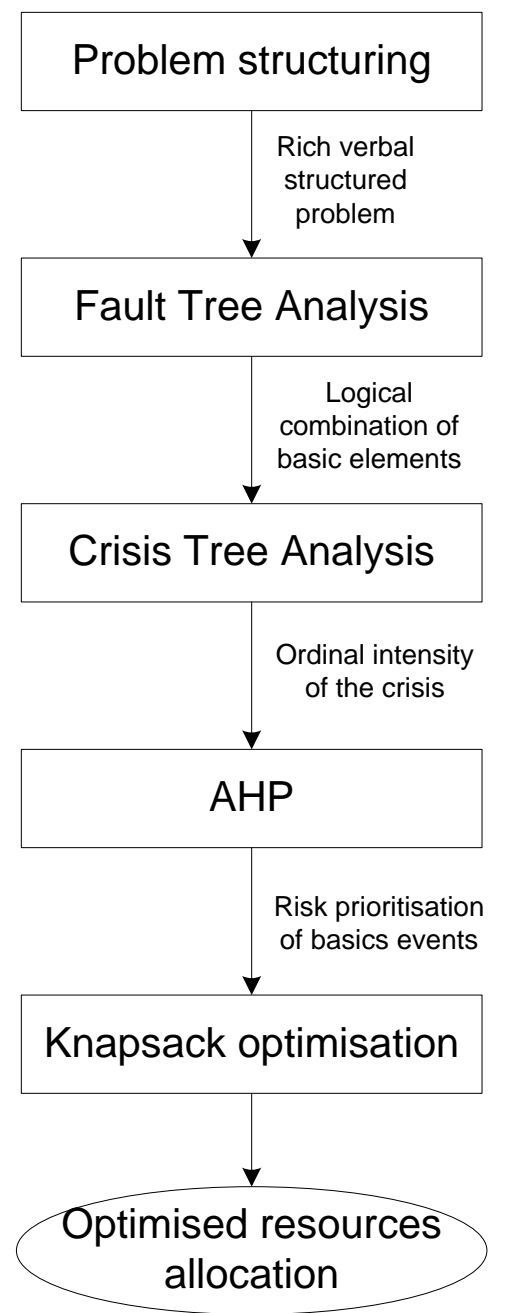

Figure 1: Input-output relationship between each methodology

\subsection{Problem structuring}

Structuring decision problems is often described to be the first and most important step towards making a rational decision. The structuring process transforms an ill-defined problem into a set of well-defined elements, relations and operations. Basically, the main goal of problem structuring is to develop a formal representation of the contributory factors in the decision problem that also includes the views, opinions and values of multiple decision makers. Problem structuring is not a solution-oriented approach, rather an approach to find the constituents of the problem. 
[Postprint version] Please cite as : Ishizaka A, Labib A, A Hybrid and Integrated Approach to Evaluate and Prevent Disasters, Journal of the Operational Research Society, 65(10), 1475-1489, 2013

A popular way to structure the problem is the hierarchical approach, which leads to more manageable sub-problems. The output of hierarchical problem structuring methodology is a better understanding of the problem which in turn acts as a pre-requisite, or an input, for subsequent methodologies used in the proposed integrated approach as shown in Figure 1.

Output: A rich verbal structured problem.

\subsection{Crisis tree analysis}

CTA represents graphically the combination of basic events or facts leading to a crisis. This technique is a further development of FTA. FTA has been widely used as a safety and reliability tool for complex systems (Zio et al. 2008, Joshua and Garber 1992, Martins and Maturana 2010, Thekdi and Lambert 2011). In both analyses, the undesired event is placed on the top of the tree and its children represent the basic events. These basic events may occur due to human errors, equipment failure or environmental interference. Tree analysis provides a logical representation of the relation between the top event (usually the main disaster) and the basic events. Its construction is always top-down, starting from the main undesired event and then developed downwards with the causes making the basic events of the tree. In FTA, the AND and OR gates are sufficient enough to describe most of the situations: a machine works or does not work. However in CTA, the output is not always binary. The magnitude of the crisis may vary depending on the number of active inputs.

For example, consider the following three events (Figure 2) and their consequences:

1) an uncontrolled manipulation lead to a lethal explosion, but the location is far away from habitations, and evacuation procedures are in place. Only one basic event occurs, it is a crisis of severity level 1. 
[Postprint version] Please cite as : Ishizaka A, Labib A, A Hybrid and Integrated Approach to Evaluate and Prevent Disasters, Journal of the Operational Research Society, 65(10), 1475-1489, 2013

2) an uncontrolled manipulation lead to a lethal explosion, location is close to habitations, but evacuation procedures are in place. Two basic events occurs, a higher number of persons are possibly killed than in case one. It is a crisis of severity level 2.

3) an uncontrolled manipulation lead to a lethal explosion, location is close to habitations and no evacuation procedure is in place. Three basics events occurs, the number of victims is possibly much higher than in the two previous cases. It is a crisis of severity level 3.

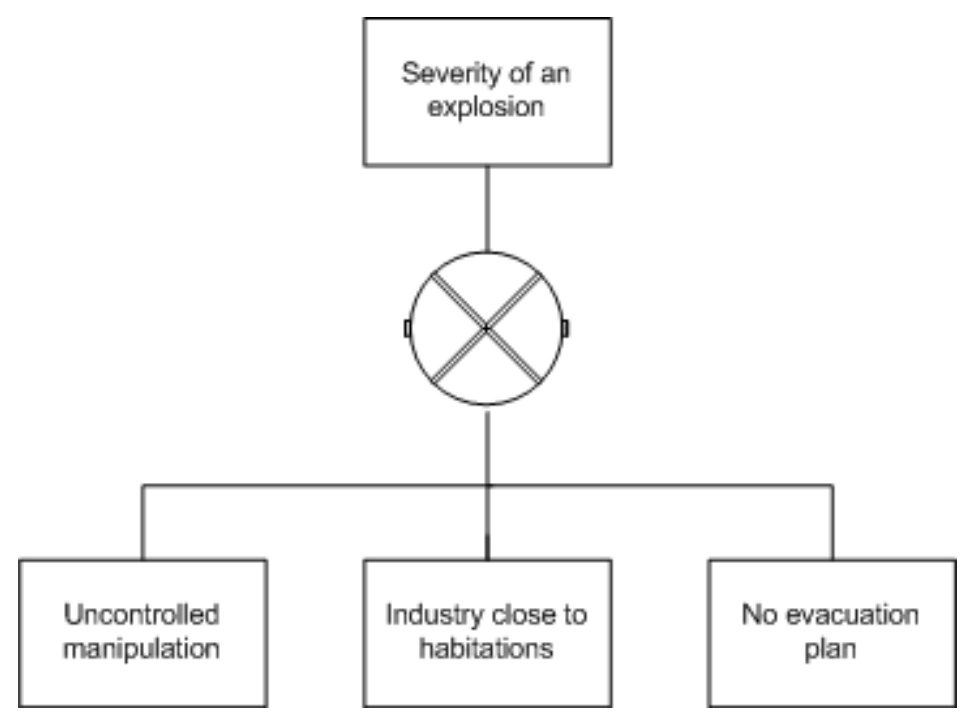

Figure 2 : Example of graph with a revolving gate

The number of events occurring has clearly an impact on the severity of the crisis. Therefore, we have introduced the new gate REVOLVING (Table 2), where the output indicates the level of the crisis. The logic table of this new gate is given in Table 3. As the output of the revolving gate can be greater than 1 , the logic table is extended in case this output feeds to another gate.

\begin{tabular}{|c|c|c|c|}
\hline Symbol & Gate name & Description & Inputs \\
\hline & REVOLVING & $\begin{array}{c}\text { The output occurs if any of its input event happen and } \\
\text { is amplified with its number }\end{array}$ & $\geq 2$ \\
\hline
\end{tabular}

Table 2: REVOLVING logic gate 
[Postprint version] Please cite as : Ishizaka A, Labib A, A Hybrid and Integrated Approach to Evaluate and Prevent Disasters, Journal of the Operational Research Society, 65(10), 1475-1489, 2013

\begin{tabular}{|c|c|c|}
\hline Input 1 & Input 2 & Output REVOLVING \\
\hline 0 & 0 & 1 \\
\hline 1 & 0 & 1 \\
\hline 0 & 1 & $\mathrm{n}$ \\
\hline 1 & 1 & $\mathrm{n}$ \\
\hline $\mathrm{n}$ & 0 & $\mathrm{n}+\mathrm{m}$ \\
\hline 0 & $\mathrm{n}$ & $\mathrm{m}+\mathrm{n}$ \\
\hline $\mathrm{n}$ & $\mathrm{m}$ & $\mathrm{n}$ \\
\hline
\end{tabular}

Table 3: Logic table of the REVOLVING gate

CTA is a powerful method for diagnostics and problem finding because it follows a logical and systematic process of breaking down a complex system into its root causes. Not only does it analyse the physical parts of the system, but also considers the intangible events including, for example, human skills and quality of the evacuation procedure. In practise, each event in the hierarchy may not have the same probability of occurrence. CTA is inherently a qualitative analytic tool and therefore, a quantitative method must also be incorporated to estimate these probabilities. This hierarchical analysis can be reused in the AHP method to quantify the priority of each basic event.

Output: A graphical modelling of the logical combination of basic events.

\subsection{Reliability Block Diagrams}

RBD are systems that are substantially equivalent to the crisis tree diagrams. Unlike the FTA model, RBD is a success oriented model: it looks at the combination that leads to system functionality. Each block in the RBD represents an actual functioning component. In RBD, the 
[Postprint version] Please cite as : Ishizaka A, Labib A, A Hybrid and Integrated Approach to Evaluate and Prevent Disasters, Journal of the Operational Research Society, 65(10), 1475-1489, 2013

system fails when the connection between input and output is totally interrupted i.e. all the possible paths from input to output are interrupted/blocked (Corporation 2007). Blocks could be arranged either in parallel or series. A parallel structure corresponds to an AND logic gate in the crisis tree diagram, whilst the series format corresponds to an OR logic gate. The new REVOLVING gate indicates the severity level of crisis. Its representation in RBD is a block series as in the OR gate but with an additional hyper-block covering each entry. The hyper-block is green if its entry is connected with its output. If a connection between input and output of the hyper-block is missing, it will turn red. The number of red hyper-blocks indicates the severity level of the crisis. Table 4 summarizes the conversion.

\begin{tabular}{|c|c|c|}
\hline Gate name & Structure & Representation \\
\hline REVOLVING & $\begin{array}{l}\text { Green or red } \\
\text { hyper-block }\end{array}$ \\
\hline
\end{tabular}

Table 4: Reliability Block Diagram representation of the REVOLVING gate

Output: A graphical success oriented modelling of the logical combination of basic events.

\subsection{Analytic Hierarchy Process}

AHP is a multi-criteria decision making (MCDM) method that helps the decision maker in solving a complex problem having multiple conflicting criteria (Saaty 1977, Saaty 1980, Ishizaka and Labib 2009). AHP has been successfully used in various domains e.g. Information Systems (Ahn and Choi 2007), Supply Chain Management (Sha and Che 2005, Akarte et al. 2001), Public services (Fukuyama and Weber 2002, Mingers et al. 2007, Pastor-Ferrando et al. 2010), Health (Lee and Kwak 1999, Li et al. 2008), Strategy (Leung et al. 2005), E-learning (Tavana 2005), Defence (Wheeler 2005), Maritime Ports (Yeo et al. 2009), and Manufacturing (Banuelas and Antony 2006) and safety has not been an exception (Paulos and Apostolakis 
[Postprint version] Please cite as : Ishizaka A, Labib A, A Hybrid and Integrated Approach to Evaluate and Prevent Disasters, Journal of the Operational Research Society, 65(10), 1475-1489, 2013

1998, Linkov et al. 2006, Steele et al. 2009, Saaty 1987, Taghipour et al. 2011). New

applications integrate AHP with other methods as mathematical programming techniques like , Data Envelopment Analysis (DEA), Fuzzy Sets, House of Quality, Genetic Algorithms, Neural Networks, SWOT-analysis (Ho and Emrouznejad 2009). This trend is especially visible in the safety sector where AHP is combined with goal programming (Bertolini and Bevilacqua 2006) Multi Attribute Utility Theory (Karydas and Gifun 2006), Bayesian analysis (Cagno et al. 2000, Carnero 2006), Bayesian belief networks (Ha and Seong 2004), Failure Mode Effect and Criticality Analysis Technique (FMECA) (Lopez et al. 2010), Success Likelihood Index Method (SLIM) (Park and Lee 2008), Fuzzy CREAM (Marseguerra et al. 2007), Fuzzy logic (Yang et al. 2009), Vector Projection Method (Chen and Cai 2003), Multivariate Regression Analysis (Mallor et al. 2008), Probability Risk Assessment (PRA) (Li et al. 2009) and Selective Attention Effectiveness (Ha and Seong 2009). In this paper, we will describe in sections 3.4, a new integration of AHP with CTA. CTA produces a logical combination of basic events and measures the severity of the crisis. Then, AHP calculates, in the constructed crisis tree, the criticality of each basic event in order to decide where urgent safety actions are needed. AHP has the advantage of permitting a hierarchical structure of the problem, which provides users with a better focus on specific criteria and sub-criteria when allocating weights. The decision goal is located on top of the hierarchy. The children of the tree are the criteria and subcriteria to be satisfied by each alternative. The leaves on this hierarchy are the alternatives to be considered. At the exception of the leaves, the AHP structure is similar to the one discussed for CTA i.e. the goal is the undesired event and the criteria are the basic events. Therefore, AHP can easily be adopted to measure the criticality of the basic events.

The main feature of AHP is the pairwise comparison of criteria at the same hierarchic level. The method of pairwise comparisons provides more accurate results than direct evaluations, 
[Postprint version] Please cite as : Ishizaka A, Labib A, A Hybrid and Integrated Approach to Evaluate and Prevent Disasters, Journal of the Operational Research Society, 65(10), 1475-1489, 2013

primarily due to the fact that the decision maker is asked to concentrate only on two elements at a time (Millet 1997, Ishizaka et al. 2011, Elliott 2010). These comparisons are entered in a positive reciprocal matrix, A. The eigenvalue method is used to calculate the priorities from this matrix:

$$
\mathbf{A} \cdot \mathbf{p}=\lambda_{\max } \cdot \mathbf{p}
$$

where $\mathbf{A}$ is the comparison matrix

$\mathbf{p}$ is the priorities vector

$\lambda_{\text {max }}$ is the maximal eigenvalue

In order to declare the comparison matrix consistent enough for calculating credible priorities, it must pass a consistency check (2). Consistency Ratio (CR) is defined as:-

$$
\mathrm{CR}=\mathrm{CI} / \mathrm{RI}
$$

where RI is the Random Index (the average CI of 500 randomly filled matrices)

$$
\mathrm{CI} \text { is the Consistency Index }
$$

$$
\mathrm{CI}=\left(\lambda_{\max }-n\right) /(n-1)
$$

where $n$ is the dimension of the matrix

$\lambda_{\max }$ is the maximal eigenvalue

If CR is less than $10 \%$, then the matrix is considered to have an acceptable level of inconsistency. If not, the decision makers are asked to revise their judgments in order to improve the consistency level.

Output: Prioritisation of the criticality of basics events. 
[Postprint version] Please cite as : Ishizaka A, Labib A, A Hybrid and Integrated Approach to Evaluate and Prevent Disasters, Journal of the Operational Research Society, 65(10), 1475-1489, 2013

\subsection{Knapsack optimisation}

Resources allocation problem, also called the knapsack problem, is a combinatorial optimization problem to assign the available resources to different activities. AHP has been used in conjunction with linear programming to determine the best combination of alternatives that has the largest sum of priority within the given constraints. The priorities calculated in AHP serves as coefficients of the objective function of the linear programming problem. Some example of applications are the allocation of a budget to different departments (Saaty et al. 2003), the optimisation of human resource allocation, the allocation of staff to training programs and the hiring of problem (Saaty et al. 2007), the calculation of exploitation oil quotas (Xiao et al. 1998), the optimisation of quantity order from several suppliers (Kokangul and Susuz 2009, Ghodsypour and O'Brien 1998, Özgen et al. 2008, Ting and Cho 2008) and the allocation of warehouses in a logistics distribution network (Ho et al. 2010).

In crisis management, the criteria for security must be given priority over all other criteria during the cost to benefit analysis. Security is the primary objective to be achieved that cannot be traded off against any other objective. For example, it would be a deadly mistake to prefer profitability against safety.

In the following knapsack problem, the model is formulated to select an optimal set of events to be secured under the condition of having limited resources. The objective function is to maximise security, in which the AHP priorities are incorporated as weighting factors. The events with higher priority have higher criticality. The problem is binary in nature since an event is either secured or unsecured. Mathematically the binary knapsack problem can be formulated as: 
$\operatorname{maximise} \sum_{i}^{n} c r_{i} \cdot e_{i}$

subject to : $\sum_{i}^{n} c_{i} \cdot e_{i} \leq f$

$$
e_{i} \in\{0,1\}
$$

where: $\quad e_{i}$ event $i$

$c r_{i}$ criticality of event $i$

$c_{i} \quad$ cost of event $i$

$f \quad$ available funds

Output: Optimised resource allocation.

\section{CASE STUDY OF THE BHOPAL GAS DISASTER}

\subsection{Introduction}

In this section, we will first analyse the complex set of organisational and technological factors that lead to the Bhopal disaster (section 3.2). Each basic event will be numbered in bold, used for constructing a crisis fault tree (section 3.3) and then prioritised with the AHP method (section 3.4). Finally, a safety investment will be optimised (section 3.5).

\subsection{Bhopal disaster structuring}

The problem structuring has been performed through secondary data analysis. Since the literature on the Bhopal disaster is very rich, a direct contact with the stakeholders is not necessary. Also, the disaster happened about 30 years ago, so collecting the primary data seems inappropriate as memories have faded and key persons may have disappeared. A secondary data analysis on the Bhopal disaster gives also the possibility to triangulate multiple sources.

Moreover, the case can be easily checked by other researchers (Saunders et al. 2009). In order to understand how the crisis tree diagrams in Figure 3 and Figure 4 are derived, this section 
[Postprint version] Please cite as : Ishizaka A, Labib A, A Hybrid and Integrated Approach to Evaluate and Prevent Disasters, Journal of the Operational Research Society, 65(10), 1475-1489, 2013

describes each event that caused the disaster. They are indentified in the rich verbal description by bold numbers that can also be found in the CTA diagrams given in Figure 3 and Figure 4 or in the RBD in Figure 5.

\subsubsection{Disaster background}

In 1969, the multi-national Union Carbide Corporation (UCC) established a small Indian subsidiary (Union Carbide India Ltd - UCIL) to manufacture pesticides called 'sevin' in Bhopal - a city located in the centre of India with a population of approximately 1.4 million. The Indian plant offered competitive advantages due to cheap labour and low operating costs, and an access to a rapidly expanding market. Moreover, UCIL was able to exploit the country’s lax environmental and safety regulations as India was striving to attract large corporations to industrialise the nation. The new Bhopal facility was advertised as being the facility constructed based on the twenty years of experience learnt from the UCC facility located in West Virginia, USA.

On the $3^{\text {rd }}$ December 1984, Bhopal city suffered from the major disaster originated from the Union Carbide Plant (4.8 miles away). Poisonous gases were released into the atmosphere, such as the Methyl Isocyanate (MIC). MIC was originally used in World War I and it attacks the 'wet' parts of our bodies, such as the eyes, mouth and throat. It enters the lungs where it reacts with bodily fluids drowning a person from the inside. Three thousand persons were killed immediately and many other lost their lives later (an up to date figure states 20,000). Approximately 120,000 people are still suffering from serious ill health. Considering this huge figure, the Bhopal gas disaster is considered to be one of the worst man-made disasters. 
[Postprint version] Please cite as : Ishizaka A, Labib A, A Hybrid and Integrated Approach to Evaluate and Prevent Disasters, Journal of the Operational Research Society, 65(10), 1475-1489, 2013

\subsubsection{Installation}

In 1972, a UCC internal report recommended that new plant should be built with the same standard as the West Virginia plant. The UCC engineers oversaw the design, construction and operation until the end of 1982, along with their technical support and safety reviews. After that, the Indian facility underwent cost cutting programmes in its design and construction that eventually made it incomparable to its Western counterpart. For example:-

- Stainless steel piping was replaced with carbon steel pipe, which is more corrosive (1) (Pareek 1999, Chouhan 2005).

- The safety devices in Western plants were automatically controlled with back-up devices - at Bhopal, these were manually controlled (2) (Chouhan 2005).

- In similar Western plants, computerised early warning systems sensed leaks, monitored their rates and concentrations and were linked to a telephone system to automatically dial out alerts (Varma and Varma 2005). In Bhopal, there did not exist any emergency planning measures (3).

- In Bhopal, there was no extra vent gas scrubber (VGS) installed, resulting in no redundancy (4). The equivalent plant in the USA had four VGS (Chouhan 2005).

- Similarly, only one flare tower was installed yet again resulting in no redundancy at the Bhopal facility (5). The equivalent plant in the USA had two (Chouhan 2005).

- In Bhopal, no unit storage tank to check the purity was installed between the gas manufacture and the large storage tank (6). The US plant had one (Chouhan 2005).

- Unlike the normal practice in other plants, Methyl Iso Cyanate was stored in large batches (7) (Cassels 1993, Gupta 2002, Aro et al. 1985). 
[Postprint version] Please cite as : Ishizaka A, Labib A, A Hybrid and Integrated Approach to Evaluate and Prevent Disasters, Journal of the Operational Research Society, 65(10), 1475-1489, 2013

None of the main safety features of the plant were efficient due to their design. Moreover on the night of the incident, none were operational due to an under maintenance schedule (due to under staffing).

At the local level, no emergency planning was undertaken prior to the commissioning of the plant. In the US, emergency planning is immediate and involved all of the emergency services and a public broadcasting system.

\subsubsection{Precursors leading to the disaster}

As the plant was losing money between 1980 and 1984, the workforce was reduced dramatically with no clear investment in technology to warrant this reduction (8) (Aro et al. 1985, Varma and Varma 2005). The staff trainings were given only at the time when the facility was opened. No further training was virtually provided since then (9). Information on the hazards of using MIC was kept minimal. With the high personnel turnover in Bhopal those years, very few of those trained people were still working in the facility (Lees 1996, Aro et al. 1985, Varma and Varma 2005).

The basic operations of the plant were further compromised by management decisions to operate the plant either outside its designed operating parameters or to implement revised processes to ensure continued production whilst essential components of the system were defective. These defects had the potential to make a negative impact on the safety/integrity of the plant. In fact, prior to the disaster, some of the operating incidents resulting in plant workers being killed or injured along with minor releases of toxic gases had already been reported to UCC in May 1982, that stirred them to send a team of US experts in order to inspect the Bhopal plant as part of a safety inspection. Their report, which was passed to UC's management in the USA, indicated that there was "a serious potential for sizeable releases of toxic materials either due to equipment failure, operating problems or maintenance problems thus requiring various changes 
[Postprint version] Please cite as : Ishizaka A, Labib A, A Hybrid and Integrated Approach to Evaluate and Prevent Disasters, Journal of the Operational Research Society, 65(10), 1475-1489, 2013

to reduce the danger of the plant". There is no evidence that these recommendations were ever been implemented (10) (Gupta 2002, Weir 1987, Aro et al. 1985).

\subsubsection{Direct Causes of the Accident}

The production of a deadly cloud was produced as a consequence of a cheap engineering solution to a known maintenance problem. A "jumper line" connected a relief valve header to a pressure vent header enabling water from a routine washing operation to pass to the gas storage tank 610 (11). Normally, the lines are isolated by a slip blind (a physical barrier inserted into the pipe). Line washing is the duty of an operator, while installing the slip blind is the responsibility of maintenance. However the second shift maintenance position had been eliminated some days earlier and no worker was told to insert the slip blind. The operator could not see the slip blind holder from his location and had no way to know that it was not there. The ingress of water in the tank created an uncontrollable runaway exothermic reaction. The increased temperature converted liquid MIC into gas. The reaction products passed through the process vent header to the jumper line, to the relief valve vent header, onto the vent gas scrubber and finally to the atmosphere through the atmospheric vent line. The toxic gases were discharged for 2 hours and 15 minutes (Kletz 2001, Aro et al. 1985, Varma and Mulay 2009, Varma and Varma 2005).

In process industries, accidents may occur due to two fundamental reasons; either due to lack of design integrity of the plant or due to failure in operation. At Bhopal, there was evidence attributed to both reasons. The release of toxic gases was assisted by the following defects and lapses in standard operating procedures which could have easily been averted in many instances:

- The storage gas tank number 610 was filled beyond recommended capacity (7). Functional contents gauges should have provided warning and the process halted until rectified (Shrivastava 1987, Aro et al. 1985, Varma and Varma 2005). 
[Postprint version] Please cite as : Ishizaka A, Labib A, A Hybrid and Integrated Approach to Evaluate and Prevent Disasters, Journal of the Operational Research Society, 65(10), 1475-1489, 2013

- The reserve storage tank, which was supposed to receive gas in case of emergency, was already filled (14). In fact, operators were not even sure how much MIC was in the tank because many gauges in the plant were unreliable (15). Any production should have been halted until the tank was again empty. This should have been a formal requirement: a "hold point" in the control process, before any production is allowed to continue (Cassels 1993, Shrivastava 1987, Aro et al. 1985).

- The blow down valve of the 610 tank was being repaired at the time of the accident, consequently each end was open (16) (Aro et al. 1985). The tank should have been removed from service until repaired.

- The danger alarm sirens used for warning the adjacent residential communities was switched off after 5 minutes in accordance with the revised company safety practices (17) (Lees 1996, Chouhan 2005). This signal was ignored because minor leaks were common (Varma and Varma 2005). This clearly highlights the importance of emergency procedures to be in place and continually reviewed.

- The plant superintendent did not notify external agencies of the accident and initially denied the accident had occurred (18) (Pareek 1999, Bogard 1989, Aro et al. 1985). This was a clear negligence of the management and typified the poor health and safety culture within the plant (10).

- The civic authorities did not know what actions to take because no emergency procedures existed. Moreover, they were uninformed of the hazardous materials stored in the plant (3) (Weir 1987, Shrivastava 1987, Gupta 2002, Aro et al. 1985, Varma and Varma 2005). This issue was due to the lack of good communication and established emergency procedures with local agencies and emergency services. 
[Postprint version] Please cite as : Ishizaka A, Labib A, A Hybrid and Integrated Approach to Evaluate and Prevent Disasters, Journal of the Operational Research Society, 65(10), 1475-1489, 2013

- Gauges measuring temperature and pressure in the various parts of the facility, including the crucial gas storage tanks, were so notoriously unreliable that workers ignored early signs (15) (Weir 1987, Lees 1996, Varma and Varma 2005). The company should have had a robust maintenance regime which should have prevented this, coupled with a safety culture which should have questioned any unsafe conditions (Sorensen 2002).

- The refrigeration unit keeping gas at low temperatures, and therefore making it less likely of reacting and vaporizing, had been shut off to save money (19) (Cassels 1993, Weir 1987, Gupta 2002, Aro et al. 1985, Chouhan 2005). The management clearly did not demonstrate a commitment to safety and process guarding. It was a violation of established procedures.

The failings below are attributable to design deficiencies. The reduction of safety protection devices in order to maximise profits was possible because peer reviews of designs by local safety engineers was non-existent.

- The vent gas scrubber, designed to neutralise any escaping gas, had been shut off for maintenance (20). Moreover, supervisors though it was not necessary when MIC was only stored and not produced. Even if it had been operative, post disaster inquiries revealed that the maximum pressure it could have handled was only one quarter of the pressure actually reached in the accident (21) (Weir 1987, Aro et al. 1985, Varma and Varma 2005, Chouhan 2005).

- The flare tower, designed to burn off escaping gas from the scrubber, was turned off, waiting for the replacement of a corroded piece of pipe (22). The tower, however, was inadequately designed for its task, as it was capable of handling only a quarter of the volume of the gas released (23) (Weir 1987, Aro et al. 1985, Varma and Varma 2005, Chouhan 2005).

- The water curtain, designed to neutralise any remaining gas, was too short to reach the top of the flare tower where the gas billowed out (24). A larger water spray system was 
[Postprint version] Please cite as : Ishizaka A, Labib A, A Hybrid and Integrated Approach to Evaluate and Prevent Disasters, Journal of the Operational Research Society, 65(10), 1475-1489, 2013

recommended in 1982 but was never installed (Weir 1987, Shrivastava 1987, Aro et al. 1985, Varma and Varma 2005, Chouhan 2005).

- The warning system was ineffective: the alarm on the storage tank failed to signal the increase in temperature on the night of the disaster (15) (Cassels, 1993).

From this rich verbal structured problem, a crisis tree analysis (CTA) is built in the next section.

\subsection{Bhopal Crisis Tree Analysis}

The way events came together on the night of the $2^{\text {nd }}$ December 1984 is quite unique. But the underlying causes are not unique. According to the International Confederation of Free Trade Unions and the International Federation of Chemical, Energy, and General Workers (ICFTUICEF), the factors that led to the Bhopal disaster are common (Aro et al. 1985). In this section, a crisis tree analysis will map the root causes of the disaster. Figure 3 and Figure 4 show the crisis tree analysis of Bhopal disaster. The release of toxic gas can be triggered by any of the following causes:
A. Ineffective workforce
B. Poor plant design specification
C. Poor plant maintenance
D. Inappropriate management decisions

A combination of these causes will amplify the amount of gas released; therefore a REVOLVING gate has been used. In Bhopal, all four items have contributed simultaneously to the gas release, which has magnified the disaster. The next paragraphs will detail the main events of Figure 3 and Figure 4:

A. The workforce was ineffective because it did receive an appropriate training OR it had a poor health and safety culture. 
[Postprint version] Please cite as : Ishizaka A, Labib A, A Hybrid and Integrated Approach to Evaluate and Prevent Disasters, Journal of the Operational Research Society, 65(10), 1475-1489, 2013

B. Chemical plants have a large number of redundant security systems that should stop or at least contain a gas release. Each system is autonomous and efficient by itself, which justify an AND gate. Unfortunately, in Bhopal, none of them were operative.

C. The leakage of water in the MIC tank 610 , was due to poor plant maintenance actions.

D. Any inappropriate management decision would have potentially led to gas release. The accumulation of them amplified the crisis.

E. The flare tower is ineffective if it is turned off OR incapable to deal with the amount of gas released OR no redundancy has been added (two flare towers would have been able to deal with the large amount of gas).

F. The vent gas scrubber is ineffective if it is turned off OR incapable to deal with the amount of gas released OR not redundant (two vent gas scrubber would have been able to deal with the large amount of gas).

G. A slip blind was not installed during the pipe cleaning to prevent the leakage of water AND nobody checked if it was installed.

H. The emergency is deficient if the alarm sirens are turned off OR the incident is not notified OR emergency procedures do not exist. 
[Postprint version] Please cite as : Ishizaka A, Labib A, A Hybrid and Integrated Approach to Evaluate and Prevent Disasters, Journal of the Operational Research Society, 65(10), 1475-1489, 2013

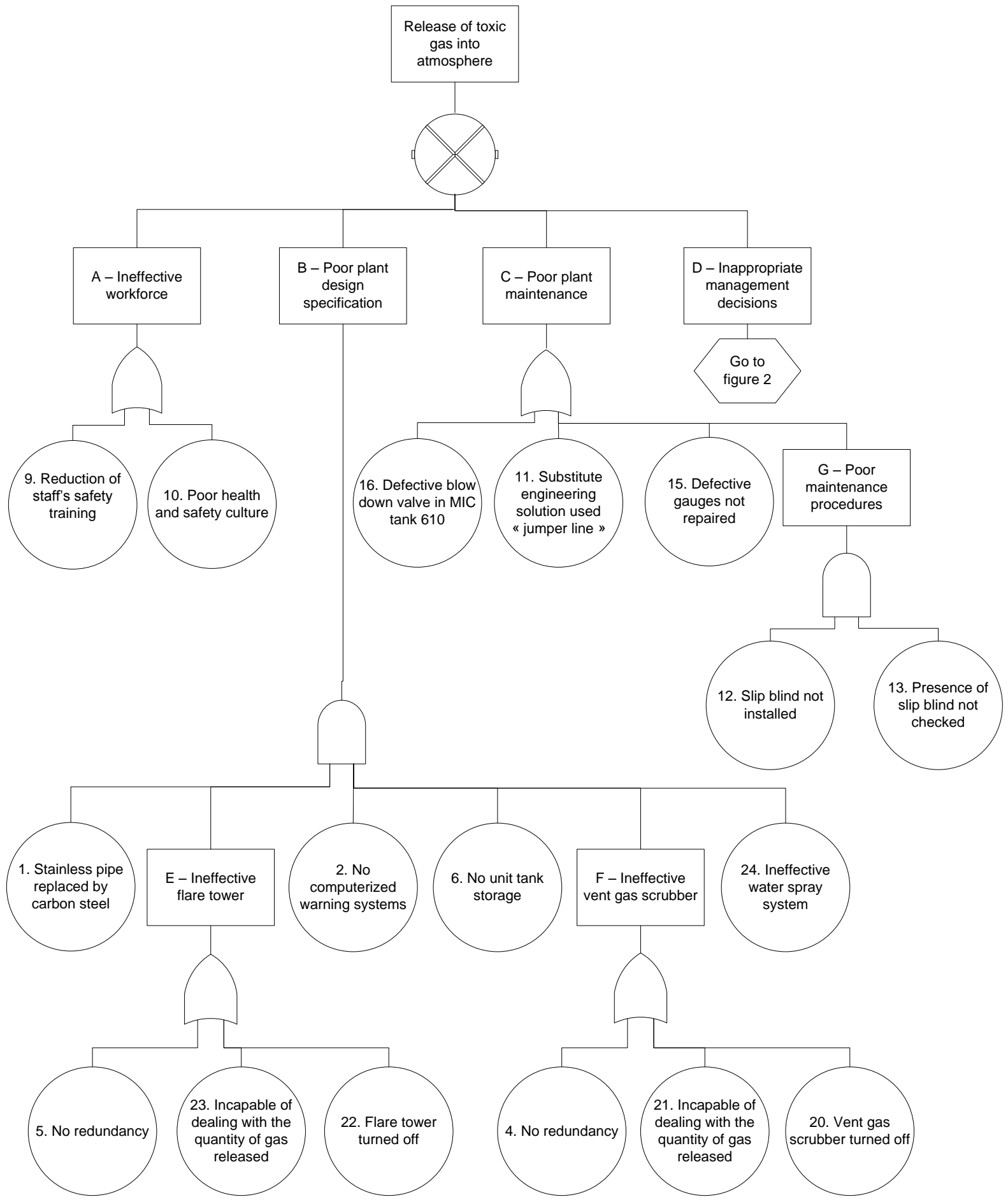

Figure 3: Crisis tree diagram of the Bhopal case 
[Postprint version] Please cite as : Ishizaka A, Labib A, A Hybrid and Integrated Approach to Evaluate and Prevent Disasters, Journal of the Operational Research Society, 65(10), 1475-1489, 2013

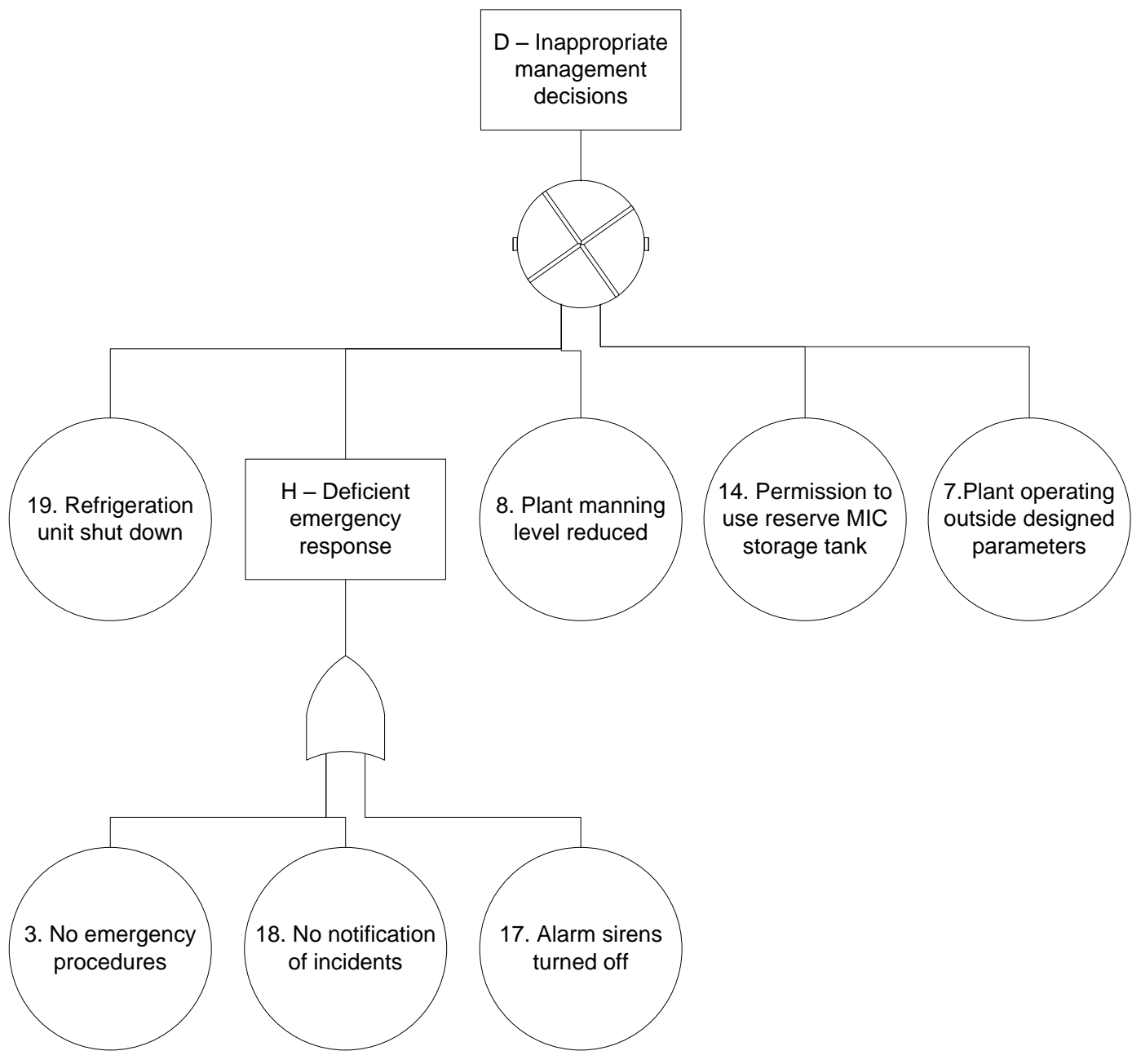

Figure 4: Crisis tree branch "inappropriate management decisions" 
[Postprint version] Please cite as : Ishizaka A, Labib A, A Hybrid and Integrated Approach to Evaluate and Prevent Disasters, Journal of the Operational Research Society, 65(10), 1475-1489, 2013

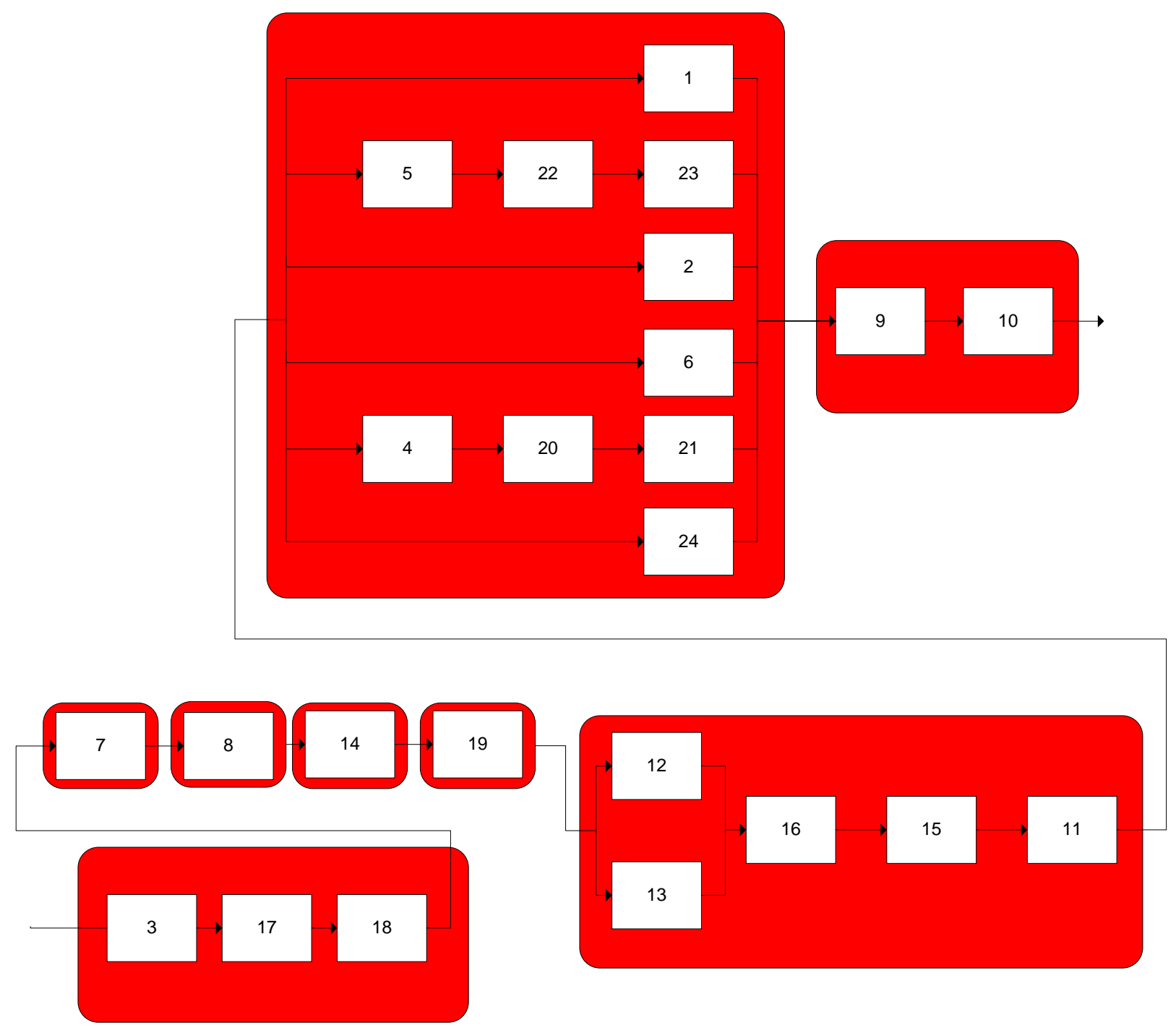

Figure 5: Reliability Block Diagram of the Bhopal case

In the next section, this crisis tree is transferred into AHP, where the criticality of each basic events is prioritised.

\subsection{Quantification of the occurrence of basic events with AHP}

In a fault tree diagram, the next step would be to give a quantitative evaluation of each basic event. If the rate of occurrence and fault duration for all basic events are known, the statistical dependency of each basic event can be calculated and the statistical expectation of the top event can be determined using, for example, Bayesian theory. In a crisis tree diagram, this technique is not applicable because we lack enough amount of pertinent data (since crisis are rare). Moreover, some basic events are purely qualitative e.g. untrained staff. Therefore, in order to 
[Postprint version] Please cite as : Ishizaka A, Labib A, A Hybrid and Integrated Approach to Evaluate and Prevent Disasters, Journal of the Operational Research Society, 65(10), 1475-1489, 2013

quantify the most critical basic events, we use AHP, which can evaluate both the quantitative and the qualitative attributes on same scale based on inputs from one or several experts (see section 2.4). The pairwise comparisons have been entered in Expert Choice software by the authors based on their experience in maintenance, informed by the literature of the Bhopal case and the opinion of an expert in asset management. Calculated criticality with (1) for each event is given in Figure 6. Note that the hierarchical structure in Figure 6, corresponds to the trees in Figure 4 and Figure 5 but in a sideway representation, where the top level of the hierarchy is at the left side of the figure. The sum of the weights of each contributing factor at any level in the hierarchy adds to unity. These weights (priorities) are indicated in the figure and are driven through a pairwise judgement as explained in section 2.4. 


\section{Goal: Release of toxic gas}

$\square$ Ineffective workforce (L: .250)

$\square$ Reduction of staff's safety training (L: .167)

Poor health and safety culture (L: .833)

$\square$ Poor plant design specification ( $\mathrm{L}:$.250)

$\square$ Staineless pipe replaced by carbon steel (L: .045)

$\square$ No computerized warning system ( $L:$.123)

$\square$ Ineffective flare tower (L: .123)

$\square$ No redundancy (L: .200)

$\square$ Incapable to deal with the quantity of gas released ( $L:$,600)

$\square$ Turned off (L: .200)

$\square$ No unit tak storage (L: .095)

$\square$ Ineffective water spray system (L: .123)

$\square \square$ Ineffetive vent gas scrubber (L: .490)

$\square$ No redundancy (L: .200)

$\square$ Incapable of dealing with the quantity of gas released (L: .600)

$\square$ Turned off (L: .200)

$\square$ Inappropriate management decisions (L: .250)

Refrigeration unit shut down (L: .438)

$\square$ Defficient emergency response (L: .081)

$\square$ No emergency procedures (L: .200)

$\square$ No notification of incidents (L: .200)

$\square$ Alarm sirens turned off (L: .600)

$\square$ Plant manning level reduced ( $\mathrm{L}:$.081)

$\square$ Permission to use MIC storage tank (L: .149)

$\square$ Plant operationg outside designed parameters ( $L:$ :250)

$\because \square$ Poor plant maintenance (L: .250)

$\square$ Defective blow down valve in MIC tank 610 (L: .125)

$\square$ Substitute engineering solution used "jumper line" (L: .375)

$\square$ Defective gauges not repaired (L: .375)

$\because \square$ Poor maintenance procedures (L: .125)

$\square$ Slip blind not installed (L: .750)

$\square$ Presence of slip blind not checked (L: .250)

Figure 6: Criticality of each event

The criticality of each basic event is used in next section as the weights of importance of the variables in the optimisation function. 
[Postprint version] Please cite as : Ishizaka A, Labib A, A Hybrid and Integrated Approach to Evaluate and Prevent Disasters, Journal of the Operational Research Society, 65(10), 1475-1489, 2013

\subsection{Safety investment optimisation}

In May 1982, a three man team from UCC in the USA inspected the Bhopal plant. In their report, they found a number of major concerns but no action was taken. In this section, we will imagine a more conscientious management, and explain how the disaster would have been avoided with an optimal investment.

As a part of an illustrative example, we have made some estimates on the costs for avoiding any basic event in the crisis tree diagram (Table 5). Rational justification and literature source for costs estimates are given in Table 5. As costs figures are historical and hypothetical (e.g. depends on the supplier at the time), they can only represent rough estimates. However, this is not an issue as the purpose of the exercise is only to illustrate the methodology.

The basic events $7,12,13,14,17,18$ are due to inappropriate decisions; no investment can directly prevent them. The basic events $11,16,15$ are part of the wider problem of poor plant maintenance. Their costs are groups under the heading C. Costs are given for a 5 year period.

\begin{tabular}{|r|l|l|l|}
\hline$\#$ & \multicolumn{1}{|c|}{ Basic event } & \multicolumn{1}{|c|}{ Justification } & Cost [m\$] \\
\hline 1 & Stainless pipe replaced by & Estimated assumption & 2.25 \\
\hline 2 & No computerized warning & Immediately after the disaster in India, & 5 \\
& system & Union Carbide shut down the MIC plant & \\
& & in West Virginia to implement a \$5 & \\
& & million new computerized warning & \\
\hline 3 & No emergency procedures & Estimated assumption of 3 man-months & 0.01 \\
& & work & 0.1 \\
\hline 4 & No VGS redundancy & Price of a new VGS from Northeast & \\
\hline
\end{tabular}


[Postprint version] Please cite as : Ishizaka A, Labib A, A Hybrid and Integrated Approach to Evaluate and Prevent Disasters, Journal of the Operational Research Society, 65(10), 1475-1489, 2013

\begin{tabular}{|c|c|c|c|}
\hline & & Controls Incorporated $^{2}$ & \\
\hline 5 & No flare tower redundancy & According to (Stone et al. 1995) & 0.05 \\
\hline 6 & No unit tank storage & Estimated assumption & 0.1 \\
\hline 7 & $\begin{array}{l}\text { Plant operating outside } \\
\text { parameters }\end{array}$ & Inappropriate decision & - \\
\hline 8 & Plant manning reduced & $\begin{array}{l}\text { Operating staff decreased of } 13 \text { persons } \\
\text { (Chouhan 2005). Estimated yearly wage } \\
10^{\prime} 000 \$ \\
5 \cdot 13 \cdot 10^{\prime} 000=0.65 \mathrm{~m} \$\end{array}$ & 0.65 \\
\hline 9 & $\begin{array}{l}\text { Reduction of staff's safety } \\
\text { training }\end{array}$ & $\begin{array}{l}\text { Training was reduced from } 18 \text { month } \\
\text { staff/year to } 1 \text { month staff/year (Chouhan } \\
\text { 2005); assuming training costs of } \\
100 £ / \text { day } \\
5 \cdot 30 \cdot 17 \cdot 100=0.255 \mathrm{~m} \$\end{array}$ & 0.255 \\
\hline 10 & $\begin{array}{l}\text { Poor health and safety } \\
\text { culture }\end{array}$ & $\begin{array}{l}\text { Long process difficult to cost. Awareness } \\
\text { actions, transfer to other sites, } \\
\text { trainings,...etc. }\end{array}$ & 0.255 \\
\hline 11 & $\begin{array}{l}\text { Substitute engineering } \\
\text { solution used «jumper } \\
\text { line } »\end{array}$ & Part of poor plant maintenance & See C \\
\hline 12 & Slip blind not installed & Inappropriate decision & - \\
\hline 13 & $\begin{array}{l}\text { Presence of slip blind not } \\
\text { checked }\end{array}$ & Inappropriate decision & - \\
\hline 14 & Permission to use reserve & Inappropriate decision & - \\
\hline
\end{tabular}

\footnotetext{
${ }^{2}$ http://www.nciweb.net/wet_scrubbers.htm
} 
[Postprint version] Please cite as : Ishizaka A, Labib A, A Hybrid and Integrated Approach to Evaluate and Prevent Disasters, Journal of the Operational Research Society, 65(10), 1475-1489, 2013

\begin{tabular}{|c|c|c|c|}
\hline & MIC storage tank & & \\
\hline 15 & $\begin{array}{l}\text { Defective gauge not } \\
\text { repaired }\end{array}$ & Part of poor plant maintenance & See C \\
\hline 16 & Defective blow down valve & Part of poor plant maintenance & See C \\
\hline 17 & Alarm sirens turned off & Inappropriate decision & - \\
\hline 18 & No notification of incidents & Inappropriate decision & - \\
\hline 19 & $\begin{array}{l}\text { Refrigeration unit shut } \\
\text { down }\end{array}$ & $\begin{array}{l}20 \$ / \text { day }(\text { Chouhan 2005) } \\
5 \cdot 20 \cdot 365=0.0365 \mathrm{~m} \$\end{array}$ & 0.0365 \\
\hline 20 & VGS turned off & Estimated cost saving of shutting it & 0.01 \\
\hline 21 & $\begin{array}{l}\text { VGS incapable of dealing } \\
\text { with the gas quantity }\end{array}$ & Estimated cost of redesign & 0.025 \\
\hline 22 & Flare tower tuned off & Estimated cost saving of shutting it & 0.01 \\
\hline 23 & $\begin{array}{l}\text { Flare tower incapable of } \\
\text { dealing with the gas } \\
\text { quantity }\end{array}$ & Estimated cost of redesign & 0.025 \\
\hline 24 & $\begin{array}{l}\text { Ineffective water spray } \\
\text { system }\end{array}$ & Estimated cost of redesign & 0.025 \\
\hline $\mathrm{C}$ & Poor plant maintenance & Estimated assumption & 0.5 \\
\hline
\end{tabular}

Table 5: Cost of each basic event over a 5 year period

A. Secure ineffective workforce

9. Reduction of staff's safety training costs

10. Poor health and safety culture

Total $\underline{\underline{0.51 \quad \mathrm{~m} \$}}$

E. Ineffective flare tower

5. No flare tower redundancy 0.05 
[Postprint version] Please cite as : Ishizaka A, Labib A, A Hybrid and Integrated Approach to Evaluate and Prevent Disasters, Journal of the Operational Research Society, 65(10), 1475-1489, 2013

22. Flare tower tuned off

23. Flare tower incapable of dealing with the gas quantity
F. Ineffective VGS

4. No VGS redundancy

20. VGS turned off

21. VGS incapable of dealing with the gas quantity

B. Poor plant design specification

1. Stainless pipe replaced by carbon steel

2. No computerized warning system

5

6. No unit tank storage

0.1

24. Ineffective water spray system

E. Ineffective flare tower

F. Ineffective VGS

0.135

Total $\underline{\underline{7.595 \mathrm{~m} \$}}$

H. Deficient emergency response

3. No emergency procedures

0.01

17. Alarm sirens turned off

0

18. No notification of incidents

0

Total $\underline{\underline{0.01 \quad \mathrm{~m} \$}}$

C. Secure poor plant maintenance

Total $\underline{\underline{0.5 \quad \mathrm{~m} \$}}$

D. Secure inappropriate management decisions

7. Plant operating outside parameters

8. Plant manning reduced

0.65 


\begin{tabular}{|ll|}
\hline 14. Permission to use reserve MIC storage tank & 0 \\
19. Refrigeration unit shut down & 0.0365 \\
H. Deficient emergency response & 0.01 \\
& Total $\underline{\underline{0.6965 \mathrm{~m} \$}}$ \\
\hline
\end{tabular}

Table 6: Costs by event

Table 6 groups costs by events. The total cost for securing all events is $9.3015 \mathrm{~m} \$$. What happens if the funding is lower than the total costs? Less critical events according to the AHP analysis will be secured later.

As an example, we assume a safety investment of $6 \mathrm{~m} \$$. Our crisis tree diagram (Figure 3 and Figure 4) is our starting point. In order to avoid any disaster, each entry of an OR and REVOLVING gate, and at least one entry of an AND gate must be safe. Therefore, our investment must first secure all OR and REVOLVING gates and then an optimal calculation is made for the AND gates. In our case, a $6 \mathrm{~m} \$$ budget allow us to secure entirely events $\mathrm{A}, \mathrm{C}$ and D but not event B. A safety budget of $4.2935 \mathrm{~m} \$$ remains to secure event $B$. What will be the events to consider for maximising the security? To answer this question, we are using the knapsack algorithm (section 2.5) with the criticality factor calculated in the section 3.7 (Table 7).

\begin{tabular}{|c|c|c|c|c|c|c|}
\hline & $\begin{array}{c}\mathrm{x}_{1} \cdot \\
\text { Stainless } \\
\text { pipe }\end{array}$ & $\begin{array}{c}\mathrm{x}_{\mathrm{E}} \cdot \\
\text { Ineffective } \\
\text { flare tower }\end{array}$ & $\begin{array}{c}\mathrm{x}_{2} \cdot \\
\text { No } \\
\text { computerized } \\
\text { warning }\end{array}$ & $\begin{array}{c}\mathrm{x}_{6} \cdot \\
\text { No unit } \\
\text { tank } \\
\text { storage }\end{array}$ & $\begin{array}{c}\mathrm{x}_{\mathrm{F}} . \\
\text { Ineffective } \\
\text { VGS }\end{array}$ & $\begin{array}{c}\mathrm{x}_{24} \cdot \\
\text { Ineffective } \\
\text { Water } \\
\text { spray } \\
\text { system }\end{array}$ \\
\hline Criticality & 0.045 & 0.123 & 0.123 & 0.095 & 0.49 & 0.123 \\
\hline Costs & 2.25 & 0.085 & 5 & 0.1 & 0.135 & 0.025 \\
\hline
\end{tabular}

Table 7: Costs and criticality of each event

The knapsack model is given by: 
[Postprint version] Please cite as : Ishizaka A, Labib A, A Hybrid and Integrated Approach to Evaluate and Prevent Disasters, Journal of the Operational Research Society, 65(10), 1475-1489, 2013

maximise $0.045 \cdot \mathrm{x}_{1}+0.123 \cdot \mathrm{x}_{\mathrm{E}}+0.123 \cdot \mathrm{x}_{2}+0.095 \cdot \mathrm{x}_{6}+0.49 \cdot \mathrm{x}_{\mathrm{F}}+0.123 \cdot \mathrm{x}_{24}$

subject to $2.25 \cdot \mathrm{x}_{1}+0.085 \cdot \mathrm{x}_{\mathrm{E}}+5 \cdot \mathrm{x}_{2}+0.1 \cdot \mathrm{x}_{6}+0.135 \cdot \mathrm{x}_{\mathrm{F}}+0.025 \cdot \mathrm{x}_{24} \leq 4.2935$

$$
\mathrm{x}_{1}, \mathrm{x}_{\mathrm{E}}, \mathrm{x}_{2}, \mathrm{x}_{6}, \mathrm{x}_{\mathrm{F}}, \mathrm{x}_{24} \in\{0,1\}
$$

In our case, the optimal solution, calculated with the Excel solver, requires to secure all the events $\mathrm{X}_{\mathrm{i}}$ at the exception of the computerized warning system $\left(\mathrm{X}_{2}\right)$.

\section{CONCLUSION}

Several methods have been developed to evaluate and mitigate risks (e.g. FTA, AHP, RBD, etc). Some of these methods have received much attention due to their simplicity, ease of use and visual display. However, all such methods have their limitations, when used on their own, due to their inherent assumptions. It would be a dramatic mistake to try to manipulate the disaster modelling in order to fit it in the method instead of the vice versa.

We have demonstrated that Fault Tree Analysis can be adapted in Crisis Tree Analysis in order to map a crisis with the introduction of the revolving gate. Similarly, Reliability Block Diagram can also map crisis with hyper-blocks as the counterpart of the revolving gate. The AHP method can be used to quantify events criticality. Their flexibility allows their integration into a new hybrid method.

In our case study, four methods have been used in conjunction. This hybrid method permits more realistic and sound decisions than any method used in isolation. This approach has been illustrated with the Bhopal disaster, where the budget allocation problem with their many subjective and objective risk evaluations has been optimised in order to maximise the safety and by consequence minimise the disaster likelihood. This approach allows taking rational and justifiable decisions, even to shut down a plant if the safety resources are not sufficient. It is therefore a generic and flexible approach, which can be easily used to prevent disasters in any field. 
[Postprint version] Please cite as : Ishizaka A, Labib A, A Hybrid and Integrated Approach to Evaluate and Prevent Disasters, Journal of the Operational Research Society, 65(10), 1475-1489, 2013

Our hybrid model can also be applied to various applications with different costing target such as the following:

- to determine the minimal budget for a minimal acceptable security,

- to determine the budget for a security with only one or $n$ redundant systems,

- to plan a rolling investment instead of a one off investment,

- to take into account flexible costs,

- to incorporate a time factor, with regular maintenance and depreciation.

This model can be useful not only for industries but also for insurance companies in order to calculate insurance premium, or the defence industry where crisis management is of great importance.

\section{Acknowledgement}

The authors would like to thank the reviewers for the comprehensive and thoughtful comments and suggestions. We wish also to thank Sajid Siraj for the proofreading of the paper.

\section{REFERENCES}

Ahmed R, Koo J, Jeong Y and Heo G (2011). Design of safety-critical systems using the complementarities of success and failure domains with a case study. Reliability Engineering and System Safety 96(1): 201-209.

Ahn B and Choi S (2007). ERP system selection using a simulation-based AHP approach: a case of Korean homeshopping company. Journal of the Operational Research Society 59(3): 322-330.

Akarte M, Surendra N, Ravi B and Rangaraj N (2001). Web based casting supplier evaluation using analytical hierarchy process. Journal of the Operational Research Society 52(5): 511-522.

Apostolakis G and Lemon D (2005). A screening methodology for the identification and ranking of infrastructure vulnerabilities due to terrorism. Risk Analysis 25(2): 361-376. 
[Postprint version] Please cite as : Ishizaka A, Labib A, A Hybrid and Integrated Approach to Evaluate and Prevent Disasters, Journal of the Operational Research Society, 65(10), 1475-1489, 2013

Aro P, Carlsen J-L, Rice A, Seminario M, Wright M, McClelland S, Vidal J, Kulkarni R, Yadav $\mathrm{R}$, Singh T and Nagarajan N (1985). The Report of the ICFTU-ICEF Mission to study the causes and Effects of the Methyl Isocyanate Gas Leak at the Union Carbide Pesticide Plant in Bhopal, Brussels/Geneva: ICFTU-ICEF.

Banuelas R and Antony J (2006). Application of stochastic analytic hierarchy process within a domestic appliance manufacturer. Journal of the Operational Research Society 58(1): 29-38.

Bertolini M and Bevilacqua M (2006). A combined goal programming-AHP approach to maintenance selection problem. Reliability Engineering and System Safety 91(7): 839848.

Bogard W (1989). The Bhopal tragedy: language, logic, and politics in the production of a hazard, San Francisco: Westview Press.

Cagno E, Caron F, Mancini M and Ruggeri F (2000). Using AHP in determining the prior distributions on gas pipeline failures in a robust Bayesian approach. Reliability Engineering and System Safety 67(3): 275-284.

Carnero C (2006). An evaluation system of the setting up of predictive maintenance programmes. Reliability Engineering and System Safety 91(8): 945-963.

Cassels J (1993). The uncertain promise of law: lessons from Bhopal, Toronto: University of Toronto Press.

Chen L and Cai J (2003). Using Vector Projection Method to evaluate maintainability of mechanical system in design review. Reliability Engineering and System Safety 81(2): 147-154.

Chouhan T (2005). The unfolding of Bhopal disaster. Journal of Loss Prevention in the Process Industries 18(4-6): 205-208.

Corporation R (2007). System Analysis Reference: Reliability, Availability and Optimization, Tucson: ReliaSoft Publishing.

Cox L (2002). Risk Analysis Foundations, Models, and Methods, Boston/Dordrecht/London: Kluwer Academic Publishers.

Elliott M (2010). Selecting numerical scales for pairwise comparisons. Reliability Engineering and System Safety 95(7): 750-763.

Ferdous R, Khan F, Sadiq R, Amyotte P and Veitch B (2009a). Handling data uncertainties in event tree analysis. Process Safety and Environmental Protection 87(5): 283-292.

Ferdous R, Khan F, Sadiq R, Amyotte P and Veitch B (2011). Fault and Event Tree Analyses for Process Systems Risk Analysis: Uncertainty Handling Formulations. Risk Analysis 31(1): 86-107. 
[Postprint version] Please cite as : Ishizaka A, Labib A, A Hybrid and Integrated Approach to Evaluate and Prevent Disasters, Journal of the Operational Research Society, 65(10), 1475-1489, 2013

Ferdous R, Khan F, Sadiq R, Amyotte P and Veitch B (2012). Handling and updating uncertain information in bow-tie analysis. Journal of Loss Prevention in the Process Industries 25(1): 8-19.

Ferdous R, Khan F, Sadiq R, Amyotte P and Veitch B (2013). Analyzing system safety and risks under uncertainty using a bow-tie diagram: An innovative approach. Process Safety and Environmental Protection 91(1-2): 1-18.

Ferdous R, Khan F, Veitch B and Amyotte P (2009b). Methodology for computer aided fuzzy fault tree analysis. Process Safety and Environmental Protection 87(4): 217-226.

Fukuyama H and Weber W (2002). Evaluating public school district performance via DEA gain functions. Journal of the Operational Research Society 53(9): 992-1003.

Gallucci R (2012). "What—me worry?" "Why so serious?": A personal view on the Fukushima nuclear reactor accidents. Risk Analysis 32(9): 1444-1450.

Ghodsypour S and O'Brien C (1998). A decision support system for supplier selection using an integrated analytic hierarchy process and linear programming. International Journal of Production Economics 56-57: 199-212.

Gupta J (2002). The Bhopal gas tragedy: could it have happened in a developed country?. Journal of Loss Prevention in the Process Industries 15(1): 1-4.

Ha J and Seong P (2004). A method for risk-informed safety significance categorization using the analytic hierarchy process and bayesian belief networks. Reliability Engineering and System Safety 83(1): 1-15.

Ha J and Seong P (2009). A human-machine interface evaluation method: A difficulty evaluation method in information searching (DEMIS). Reliability Engineering and System Safety 94(10): 1557-1567.

Ho W and Emrouznejad A (2009). Multi-criteria logistics distribution network design using SAS/OR'. Expert Systems with Applications 36(3, Part 2): 7288-7298.

Ho W, Lee C and Ho G (2010). Multiple criteria optimization of contemporary logistics distribution network problems. ORInsight 23(1): 27-43.

Ishizaka A, Balkenborg D and Kaplan T (2011). Does AHP help us make a choice? An experimental evaluation. Journal of the Operational Research Society 62(10): 18011812.

Ishizaka A and Labib A (2009). Analytic Hierarchy Process and Expert Choice: benefits and limitations. OR Insight 22(4): 201-220.

Joshua S and Garber N (1992). A Causal Analysis of Large Vehicle Accidents Through FaultTree Analysis. Risk Analysis 12(2): 173-188.

Karydas D and Gifun J (2006). A method for the efficient prioritization of infrastructure renewal projects. Reliability Engineering and System Safety 91(1): 84-99. 
[Postprint version] Please cite as : Ishizaka A, Labib A, A Hybrid and Integrated Approach to Evaluate and Prevent Disasters, Journal of the Operational Research Society, 65(10), 1475-1489, 2013

Khakzad N, Khan F and Amyotte P (2011). Safety analysis in process facilities: Comparison of fault tree and Bayesian network approaches. Reliability Engineering and System Safety 96(8): 925-932.

Khakzad N, Khan F and Amyotte P (2012). Dynamic risk analysis using bow-tie approach. Reliability Engineering \& System Safety 104(0): 36-44.

Khakzad N, Khan F and Amyotte P (2013a). Dynamic safety analysis of process systems by mapping bow-tie into Bayesian network. Process Safety and Environmental Protection 91(1-2): 46-53.

Khakzad N, Khan F and Amyotte P (2013b). Risk-based design of process systems using discrete-time Bayesian networks. Reliability Engineering \& System Safety 109(0): 5-17.

Kletz T (2001). Learing from accidents, Oxford: Gulf Professional Publishing.

Kokangul A and Susuz Z (2009). Integrated analytical hierarch process and mathematical programming to supplier selection problem with quantity discount. Applied Mathematical Modelling, 33(3), 1417-1429.

Lee C and Kwak N (1999). Information resource planning for a health-care system using an AHP-based goal programming method. Journal of the Operational Research Society, 50(12), 1191-1198.

Lees F (1996). Loss prevention in the process industries, Oxford: Butterworth-Heinermann.

Leung L, Lam K and Cao D (2005). Implementing the balanced scorecard using the analytic hierarchy process \& the analytic network process. Journal of the Operation Research Society 57(6): 682-691.

Li H, Apostolakis G, Gifun J, VanSchalkwyk W, Leite S and Barber D (2009). Ranking the Risks from Multiple Hazards in a Small Community. Risk Analysis 29(3): 438-456.

Li X, Beullens P, Jones D and Tamiz M (2008). An integrated queuing and multi-objective bed allocation model with application to a hospital in China. Journal of the Operation Research Society 60(3): 330-338.

Lindell M and Perry R (1990). Effects of the Chernobyl Accident on Public Perceptions of Nuclear Plant Accident Risks. Risk Analysis 10(3): 393-399.

Linkov I, Satterstrom F, Kiker G, Seager T, Bridges T, Gardner K, Rogers S, Belluck D and Meyer A (2006). Multicriteria Decision Analysis: A Comprehensive Decision Approach for Management of Contaminated Sediments. Risk Analysis 26(1): 61-78.

Lopez F, Di Bartolo C, Piazza T, Passannanti A, Gerlach J, Gridelli B and Triolo F (2010). A Quality Risk Management Model Approach for Cell Therapy Manufacturing. Risk Analysis 30(12): 1857-1871. 
[Postprint version] Please cite as : Ishizaka A, Labib A, A Hybrid and Integrated Approach to Evaluate and Prevent Disasters, Journal of the Operational Research Society, 65(10), 1475-1489, 2013

Mallor F, García-Olaverri C, Gómez-Elvira S and Mateo-Collazas P (2008). Expert JudgmentBased Risk Assessment Using Statistical Scenario Analysis: A Case Study-Running the Bulls in Pamplona (Spain). Risk Analysis 28(4): 1003-1019.

Marseguerra M, Zio E and Librizzi M (2007). Human Reliability Analysis by Fuzzy "CREAM". Risk Analysis 27(1): 137-154.

Martins M and Maturana M (2010). Human Error Contribution in Collision and Grounding of Oil Tankers. Risk Analysis 30(4): 674-698.

Millet I (1997). The effectiveness of alternative preference elicitation methods in the Analytic Hierarchy Process. Journal of Multi-Criteria Decision Analysis 6(1): 41-51.

Mingers J, Liu W and Meng W (2007). Using SSM to structure the identification of inputs and outputs in DEA. Journal of the Operational Research Society 60(2): 168-179.

Özgen D, Önüt S, Gülsün B, Tuzkaya R and Tuzkaya G (2008). A two-phase possibilistic linear programming methodology for multi-objective supplier evaluation and order allocation problems. Information Sciences 178(2): 485-500.

Pareek K (1999). The managemnet did not adhere to safety norms. Interview. Down to Earth, 56.

Park K and Lee J (2008). A new method for estimating human error probabilities: AHP-SLIM. Reliability Engineering and System Safety 93(4): 578-587.

Pastor-Ferrando J, Aragones-Beltran P, Hospitaler-Perez A and Garcia-Melon M (2010). An ANP- and AHP-based approach for weighting criteria in public works bidding. Journal of the Operational Research Society 61(6): 905-916.

Paté-Cornell E and Dillon R (2001). Probabilistic risk analysis for the NASA space shuttle: a brief history and current work. Reliability Engineering and System Safety 74(3): 345-352.

Paulos T and Apostolakis G (1998). A Methodology to Select a Wire Insulation for Use in Habitable Spacecraft. Risk Analysis 18(4): 471-484.

Rathnayaka S, Khan F and Amyotte P (2011a). SHIPP methodology: Predictive accident modeling approach. Part I: Methodology and model description. Process Safety and Environmental Protection 89(3): 151-164.

Rathnayaka S, Khan F and Amyotte P (2011b). SHIPP methodology: Predictive accident modeling approach. Part II. Validation with case study. Process Safety and Environmental Protection 89(2): 75-88.

Rathnayaka S, Khan F and Amyotte P (2012). Accident modeling approach for safety assessment in an LNG processing facility. Journal of Loss Prevention in the Process Industries 25(2): 414-423.

Saaty T (1977). A scaling method for priorities in hierarchical structures. Journal of Mathematical Psychology 15(3): 234-281. 
[Postprint version] Please cite as : Ishizaka A, Labib A, A Hybrid and Integrated Approach to Evaluate and Prevent Disasters, Journal of the Operational Research Society, 65(10), 1475-1489, 2013

Saaty T (1980). The Analytic Hierarchy Process, New York: McGraw-Hill.

Saaty T (1987). Risk-Its Priority and Probability: The Analytic Hierarchy Process. Risk Analysis 7(2): 159-172.

Saaty T, Peniwati K and Shang J (2007). The analytic hierarchy process and human resource allocation: Half the story. Mathematical and Computer Modelling 46(7-8): 1041-1053.

Saaty T, Vargas L and Dellmann K (2003). The allocation of intangible resources: the analytic hierarchy process and linear programming. Socio-Economic Planning Sciences 37(3): $169-184$.

Saunders M, Lewis P and Thornhill A (2009). Research Methods for Business Students, Harlow: Pearson.

Sha D and Che Z (2005). Supply chain network design: partner selection and production//distribution planning using a systematic model. Journal of the Operational Research Society 57(1): 52-62.

Shrivastava P (1987). Bhopal: Anatomy of Crisis, Cambridge: Ballinger Publishing Company.

Skogdalen J and Vinnem J (2012). Quantitative risk analysis of oil and gas drilling, using Deepwater Horizon as case study. Reliability Engineering and System Safety 100(0): 5866.

Sorensen J (2002). Safety culture: a survey of the state-of-the-art. Reliability Engineering and System Safety 76(2): 189-204.

Steele K, Carmel Y, Cross J and Wilcox C (2009). Uses and Misuses of Multicriteria Decision Analysis (MCDA) in Environmental Decision Making. Risk Analysis 29(1): 26-33.

Stone D, Lynch S and Pandullo R (1995). Flares', [online], available: http://www.gasflare.org/pdf/Flare_Type.pdf [accessed

Taghipour S, Banjevic D and Jardine A (2011). Prioritization of medical equipment for maintenance decisions. Journal of the Operational Research Society 62(9): 1666-1687.

Tavana M (2005). A priority assessment multi-criteria decision model for human spaceflight mission planning at NASA. Journal of the Operational Research Society 57(10): 11971215.

Thekdi S and Lambert J (2011). Decision Analysis and Risk Models for Land Development Affecting Infrastructure Systems. Risk Analysis 32(7): 1253-1269.

Ting, S.-C. and Cho, D. (2008) 'An integrated approach for supplier selection and purchasing decisions. Supply Chain Management: An international journal 13(2): 116 - 127.

Todinov M (2006). Reliability Analysis Based on the Losses from Failures. Risk Analysis 26(2): 311-335. 
[Postprint version] Please cite as : Ishizaka A, Labib A, A Hybrid and Integrated Approach to Evaluate and Prevent Disasters, Journal of the Operational Research Society, 65(10), 1475-1489, 2013

Varma D and Mulay S (2009). Methyl Isocyanate: the Bhopal gas' in Gupta, R., ed. Handbook of Toxicology of Chemical Warfare Agent, New York: Elsevier.

Varma R and Varma D (2005). The Bhopal Disaster of 1984. Bulletin of Science, Technology \& Society 25(1): 37-45.

Vuilleumier F, Weatherill A and Crausaz B (2002). Safety aspects of railway and road tunnel: example of the Lötschberg railway tunnel and Mont-Blanc road tunnel. Tunnelling and Underground Space Technology 17(2): 153-158.

Weir D (1987). The Bhopal Syndrome London: Earthscan publications Limited.

Wheeler S (2005). An analysis of combined arms teaming for the Australian defence force. Journal of the Operational Research Society 57(11): 1279-1288.

Xiao W, Liu Z, Jiang M and Shi Y (1998). Multiobjective linear programming model on injection oilfield recovery system. Computers \& Mathematics with Applications 36(5): 127-135.

Yang Z, Wang J, Bonsall S and Fang Q (2009). Use of Fuzzy Evidential Reasoning in Maritime Security Assessment. Risk Analysis 29(1): 95-120.

Yeo G, Song D, Dinwoodie J and Roe M (2009). Weighting the competitiveness factors for container ports under conflicting interests. Journal of the Operational Research Society 61(8): 1249-1257.

Youngblood R (1998). Applying Risk Models to Formulation of Safety Cases. Risk Analysis 18(4): 433-444.

Zio E, Baraldi P and Popescu I (2008). A Fuzzy Decision Tree for Fault Classification. Risk Analysis 28(1): 49-67. 